\title{
EL QUIJOTE DE AVELLANEDA Y LA CONSTITUCIÓN DE UNA REFUTACIÓN DEL MENSAJE CERVANTINO
}

\section{AVELLANEDA'S QUIXOTE AND THE CONSTITUTION OF A REFUTATION OF CERVANTES' MESSAGE}

\author{
John O’Kuinghttons Rodríguez \\ Universidad de São Paulo, Brasil \\ johnochile@gmail.com
}

\begin{abstract}
Resumen:
Analizamos la cuestión de las aspiraciones de movilidad social como una de las posibles motivaciones que pudo haber orientado la construcción del Quijote de Miguel de Cervantes y la consecuente respuesta de Fernández de Avellaneda como refutación ideológica destinada a consagrar la estabilidad de las jerarquías sociales. Para lo particular, avalaremos nuestro estudio con contribuciones de Iffland (1999) y Gómez Canseco $(2005 ; 2014)$ en lo relativo a la posición ideológica de Avellaneda; asimismo, nos apoyaremos en los conceptos de ideología según van Djik (1999) y de Aparatos Ideológicos del Estado (AIE) y Aparatos Represivos del Estado (ARE), de Althusser (2013).
\end{abstract}

Palabras clave: Ideología, Reversibilidad, Movilidad social, Aparatos Ideológicos del Estado, Aparatos Represivos del Estado.

\begin{abstract}
:
In this article we analyze the expectation of social mobility as one of the possible motivations that may have guided Miguel de Cervantes on the creation of his capital novel and on the resulting answer from Fernández de Avellaneda as an ideological refutation intended to support the stability of social hierarchies. We will base our study on Iffland's (1999) and Gómez Canseco's (2005; 2014) analysis of Avellaneda's ideological position and on the concepts of ideology according to van Djik (1999) and to Althusser's State Ideological Systems and State Repressive Systems (2013).
\end{abstract}

Keywords: Ideology, Reversibility, Social removal, State Ideological Systems, State Represive Systems.

Recibido: 10 de abril de 2019

Aceptado: 14 de mayo de 2019 


\section{Introducción}

\section{El eje político-social}

En un luminoso preámbulo (El ingenioso hidalgo don Quijote de La Mancha, de Alonso Fernández de Avellaneda, Biblioteca Nueva, 2005, 2ª edición), el académico Luis Gómez Canseco señala que Avellaneda, el más célebre y comentado de los epígonos de Cervantes, debió concebir su imitación con el objetivo de refutar ideológicamente a su modelo ${ }^{1}$. No obstante y pese a su relevancia, dicha motivación no figura de modo explícito en las declaraciones que sirven de prefacio a su novela. Tal presupuesto se sustenta en la probabilidad de que el oculto imitador haya percibido en la narración cervantina una propuesta de relativización del orden político y social que amenazaba la estabilidad de los Aparatos Ideológicos del Estado ${ }^{2}$ y de las jerarquías sociales ${ }^{3}$.

Para entender apropiadamente esta posición ideológica, vale mencionar que los siglos XVI y XVII se caracterizaron por un importante dinamismo social motivado por cuestiones tan complejas como la identidad, el ajuste político, la movilidad social y la convivencia de comunidades religiosas bajo la férula del catolicismo. Los contemporáneos de Cervantes, explica Feros (2005), se preguntaban hasta qué punto las orientaciones ideológicas e

\footnotetext{
${ }^{1}$ A sabiendas de las múltiples definiciones que se han propuesto del concepto de ideología, hemos optado por seguir la razonada por Teun van Dijk: "Las ideologías se pueden definir sucintamente como la base de las representaciones sociales compartidas por los miembros de un grupo. Esto significa que las ideologías les permiten a las personas, como miembros de un grupo, organizar la multitud de creencias sociales acerca de lo que sucede, bueno o malo, correcto o incorrecto, según ellos, y actuar en consecuencia." (Van Dijk 21). A ello agrega que las ideologías han sido tradicionalmente comprendidas como sistemas de ideas socialmente compartidas. A renglón seguido reafirma el concepto de creencia por sobre el de idea, al que le atribuye una vaguedad que dificulta su aplicación. Creencias e ideologías son susceptibles de cambios en el tiempo, y lo propio vale para el llamado sentido común.

${ }^{2}$ Para la categorización de los aparatos de poder hemos recogido dos contribuciones de Louis Althusser, quien en su ensayo "Ideología y Aparatos Ideológicos del Estado (Notas para una Investigación)" (2013) (trad. del autor) propone los conceptos de Aparatos Ideológicos del Estado (AIE) y Aparatos Represivos del Estado (ARE). Sobre los primeros, el pensador los define como "un cierto número de realidades que se presentan al observador inmediato bajo la forma de instituciones distintas y especializadas" (trad. del autor) (Althusser 114). Dado que estos aparatos se constituyen en áreas diversas, los AIE pueden ser religiosos, escolares, familiares, jurídicos, políticos y culturales. Asimismo, los AIE funcionan por la ideología, mientras los ARE se manifiestan por la violencia. Al tratar la cuestión de la Iglesia como aparato ideológico (lo cual es particularmente constitutivo en el Quijote de Avellaneda debido a la firme imbricación que ocurre entre clero y nobleza), Althusser sostiene que este era el AIE por excelencia en el período pre capitalista, debido a que, por una parte, operaba en el ámbito religioso y escolar, y, por otra, porque controlaba la difusión de la información y la cultura. La posición pro clerical de Avellaneda aspirará, pues, a validar la estabilidad de un orden social en desmedro de otro. En este estudio nos remitiremos a los conceptos de Althusser por sus respectivas siglas (AIE-ARE).

${ }^{3}$ Una refutación ideológica condice con la transformación del proyecto cervantino. Al respecto, Hanno Ehrlicher sostiene que la ficción de Avellaneda estimuló a Cervantes y lo indujo a "proseguir su propio artificio narrativo exponiéndolo y reflexionándolo en la narración de una forma todavía más consciente." (Ehrlicher 63). Blasco confirma esta aserción recordando que Avellaneda transforma a su modelo en algo diametralmente distinto (Blasco 1-2). Por otra parte, Villalobos destaca las circunstancias temporales que condicionan un procedimiento de recreación artística como el de Avellaneda: "Las diferentes y a la vez constantes relecturas, interpretaciones y reescrituras a las que ha estado sometida la obra cervantina se enmarcan dentro de ciertas modalidades interpretativas que están en directa relación y que corresponden a los contextos de recepción -sean estos ideológicos, culturales, educativos, etc.- en los que están inscritos. (...) El procedimiento de reescritura es complejo, y no solo intervienen los cambios textuales, sino que, además, en él actúan, como ya se ha mencionado, las circunstancias contextuales con sus ideologías imperantes, los nuevos receptores, la acción del editor sobre la obra y, dentro de esto último, las intenciones que el editor quiere entregar a sus lectores mediante su trabajo de reescritura." (Villalobos 123124).
} 
institucionales instauradas por los Reyes Católicos permitían responder a las necesidades y cambios que se operaban en su presente. Es sabido que en el siglo XVI gozaba de importante vitalidad la idea de que el poder regio proviene directamente de Dios y que la desobediencia o la devaluación del primero implicaba, consecuentemente, la desobediencia y devaluación del segundo. A inicios del siglo XVII se pensaba que el mejor sistema gubernamental era la monarquía hereditaria y jerarquizada. La novela de Avellaneda sugiere con diversos intersticios que su autor adhería concienzudamente a este principio ordenador y mantenedor de las prebendas institucionalizadas a través de los AIEs.

Esta relación entre las estructuras sociales y los ejes de poder fue, no obstante, progresivamente cuestionada. Bajo Felipe II y Felipe III se atribuyó la inestabilidad política al "incremento del poder e independencia de los Consejos y otras instituciones que representaban a los reinos" (FEROS, 2005: 68). Para impedirla se propuso que la monarquía debía renovar las instituciones para configurar un sistema más ejecutivo. No se trataba de favorecer la concentración del poder sino de afirmar la potestad de la monarquía como única capaz de entender las necesidades políticas y de promover soluciones que velasen ante todo por el bien común.

Es probable que los cambios más significativos en el ámbito institucional durante la transición del siglo XVI al XVII, sigue Feros (2005), hayan sido la consagración del valido y la creación de una junta privada. Además de estas reformas se impuso como exigencia la lealtad al monarca para acceder a nombramientos, lo cual forjó y reforzó el vínculo de los patronazgos. Es fama que Cervantes no se avino con este tipo de relaciones, algo que Avellaneda no dejó escapar y que recordó en su prefacio retomando lo que aquel había escrito en su respectivo prólogo:

Y pues Miguel de Cervantes es ya de viejo como el castillo de San Cervantes y, por los años, tan mal contentadizo que todo y todos le enfadan, y por ello está tan falto de amigos que, cuando quisiera adornar sus libros campanudos, había de ahijarlos, como él dice, al preste Juan de las Indias o al emperador de Trapisonda (...) (Fernández de Avellaneda, 2014:8) 
El duque de Lerma, valido que ofició entre 1598 y 1618, defendió que la construcción de una nueva monarquía implicaba la conciliación entre el respeto a los reinos y la unificación de la monarquía. Hay que considerar el hecho de que estas vindicaciones ocurrían en un contexto de elevada catolización de la sociedad, signada por el proyecto contrarreformista, que ayudó a definir un proceso de consagración del rey como defensor de la fe. Por otra parte, esta aceptación del catolicismo como gestor de unidad nacional comprometió el ejercicio de la tolerancia hacia otras comunidades, como bien lo explica Feros:

El principal resultado de una ideología de este cariz era la adopción de una visión puritana de la política, en la que la defensa de la verdad católica (la única verdad) se constituía en motor político fundamental, y en la que la tolerancia hacia los heréticos y rebeldes, tanto propios como aquellos que habitaban otras monarquías debía quedar totalmente erradicada. (Feros 90)

La defensa de la intolerancia convocaba sentimientos encontrados y contradictorios, como por ejemplo, el que se guardaba hacia los moriscos. Como indica Vincent (2005), podía haber relaciones razonablemente provechosas entre moriscos y cristiano viejos, pero estas armonías estaban empañadas por la desconfianza que estos siempre sintieron por aquellos. Paralelamente, en el grueso de la sociedad se asentaba el gran valor concedido a los linajes. Avellaneda será eco de estos juicios a lo largo de toda su novela. Las ansias de mejoramiento social explican el elevado dinamismo de los desplazamientos territoriales, a tal punto que la venta y la posada se constituyeron en espacios de convergencia para diferentes grupos sociales, tal como se advierte en diversos pasajes del primer Quijote. Parte importante del cuadro social que dio base a la literatura de la época puede compendiarse del siguiente modo:

El Consejo Real recomendó en febrero de 1619 la clausura de escuelas en los medios rurales para que los hijos de los campesinos no flirtearan con la idea de dejar el cultivo de la tierra (...) Gran parte del inmovilismo social y político que era la base de la monarquía absoluta se centraba precisamente en la inmovilidad física, literal (...) la virtud mayor era la 
obediencia, el ceñirse a la autoridad del rey y de sus representantes, basada, a su vez, en la autoridad divina. (Iffland 229)

La complejidad de estos tiempos, claro está, no fue ajena a las preocupaciones de Cervantes. Ignacio Padilla (2005) ha entendido al autor como un artista "institucional y subversivo", un hombre en quien colidieron la crítica humanista a los estamentos sociales y el deseo de pertenecer a estos. Idéntica opinión es la que defiende Close, para quien Cervantes es un relativista que, sin embargo, "cede ante la Iglesia católica y el orden establecido por el Estado" (Close 267).

Avellaneda, menos complejo, y más prefigurado, habría de responder al signo ideológico cervantino a través de una asaz controvertida creación.

\section{Una probable motivación de Cervantes}

Por la lectura de su obra capital, se puede colegir que Cervantes no sólo creía en la movilidad social, sino que la atribuía a los méritos personales antes que a los estigmas de la herencia. Prueba de ello se constata, por ejemplo, en la argumentación ideológica que don Quijote expone en 6-II. En esta línea, James Iffland (1999) ha sostenido que Cervantes entendió y dio cauce narrativo a las aspiraciones sociales de los grupos menos favorecidos. Hay indicios, agrega, que permiten postular que la insistencia en el ascenso social que redunda en 1615 sea una sutil contrarrefutación ideológica dirigida a Avellaneda, quien había tratado el problema de un modo simplista y taxativo, según dejan entender, por ejemplo, señales como la facilidad (y la consiguiente defensa del trabajo rural) con que Sancho dimite de un alto cargo y recupera la sencillez de su antigua ocupación.

La primera muestra de cómo gravita la movilidad social en la narración cervantina es el atrevimiento de don Quijote al atribuirse el título de don, osadía que molestó tanto a otros hidalgos que llegaron a acusarlo de arribista, según se lee en un comentario de Sancho ${ }^{4}$ sobre la imagen social que ambos han provocado:

(...) el vulgo tiene a vuestra merced por grandísimo loco, y a mí por no menos mentecato. Los hidalgos dicen que, no

\footnotetext{
${ }^{4}$ Vale recordar que al inicio en su gobierno (45-II), el escudero tratará de abolir el don para fomentar la igualdad en su reino.
} 
conteniéndose vuestra merced en los límites de la hidalguía, se ha puesto don y se ha arremetido a caballero con cuatro cepas y dos yugadas de tierra y con un trapo atrás y otro adelante. (Cervantes, 460$)^{5}$

La segunda evidencia de arribismo que don Quijote ostentará en el curso de su carrera es la muy temprana promesa de nombrar a Sancho gobernador de una ínsula. Cumplido, pues, el capítulo 7-I el hidalgo ya ha realizado dos resonados encumbramientos que no pasarán inadvertidos para Avellaneda. El ascenso prometido al escudero se impondrá sobre la acusación de falta de decoro del estilo cervantino al permitir que Sancho se exprese de un modo inconcebible para un campesino según se revela en 5-II. Para dar sustento verosímil a este atrevimiento, Cervantes habrá de valerse de lo que a esas alturas de la novela ya había ensayado con soltura: la transferencia del relato a más de un narrador. Al afirmar que el referido capítulo es tenido por apócrifo elimina la necesidad de medirse con el decoro prescriptivista y replantea de un modo singular la verosimilitud narrativa.

Aún en relación al escudero, recordemos que al final de la primera parte Sancho se encuentra con su esposa, a la que augura no solo nuevas aventuras y la certeza de su nombramiento, sino que ella misma será tratada de señora por vasallos que la servirán. Pero es en la segunda parte donde ocurre el mayor desborde de las pretensiones arribistas de Sancho. En 5-II el escudero mantiene una conversación con su esposa, en la que contrastan el ensueño gubernamental del escudero con la prudencia con que Teresa intenta devolverlo a la realidad. Dicho intento está alineado a la ideología de inmovilidad social que les conviene propagar a las clases favorecidas, según se constata en más de un ejemplo. Recordemos, verbigracia, la respuesta que Teresa da a Sancho cuanto a la aspiración de casar a Sanchica con alguien encumbrado: "Eso no, Sancho -respondió Teresa-: casadla con su igual, que es lo más acertado" (Cervantes 475). Y luego, ante la obstinación del marido, la mujer lo interpela del siguiente modo:

Medíos, Sancho, con vuestro estado -respondió Teresa-; no os queráis alzar a mayores, y advertid el refrán que dice: "Al hijo

\footnotetext{
${ }^{5}$ Para entender debidamente esta imputación hay que subrayar que históricamente dicha forma de tratamiento se aplicó primero a los reyes, se extendió a cargos eclesiásticos y más tarde a algunos hidalgos, que debían estar debidamente registrados en un padrón. Felipe III decretó que el uso de don se restringiera a obispos, condes, mujeres e hijas de hidalgos, además de los hijos de personas tituladas.
} 
de tu vecino límpiale las narices y métele en tu casa" (Cervantes 475).

Como adelantamos, poco después conocemos una intervención de Sancho calificada de apócrifa debido a su lenguaje. Se trata de una evidencia significativa de los juicios propalados entonces sobre movilidad social. La siguiente muestra enseña que Sancho está consciente de la reacción que tendría entre la nobleza un casamiento arribista como el que ha entrevisto para su hija:

Y cásese a Mari Sancha con quien yo quisiere, y verás cómo te llaman a ti doña Teresa Panza, y te sientas en la iglesia sobre alcatifa, almohadas y arambeles, a pesar y despecho de las hidalgas del pueblo (...) Y en esto no hablemos más, que Sanchica ha de ser condesa, aunque tú más me digas. (Cervantes 476).

La contención de Teresa Panza cambiará progresivamente hasta asumir las mismas proporciones emocionales que su marido. Así se advierte cuando recibe una carta de la duquesa en 50-II. Finalmente, y como si se tratara de un proceso familiar estratificado, el cuestionamiento al afán de encumbramiento queda a cargo de la hija, quien le enrostra a la madre:

Pluguiese a Dios que fuese antes hoy que mañana, aunque dijesen los que me viesen ir sentada con mi señora madre en aquel coche: "Mirad la tal por cual, hija del harto de ajos, y cómo va sentada y tendida en el coche, como si fuera una papesa!” (Cervantes 754).

Más tarde, y por boca de Sancho, Cervantes sugerirá que la movilidad social, aun cuando es expresión legítima de los afanes de mejoramiento vital, puede comprometer la dignidad de los sujetos y aun arriesgarse a la enajenación debido a los múltiples condicionantes que impone la sociedad:

Yo no nací para ser gobernador, ni para defender ínsulas ni ciudades de los enemigos que quisieren acometerlas, mejor se me entiende a mí de arar y cavar, podar y ensarmentar las viñas, que de dar leyes ni de defender provincias ni reinos (Cervantes 772). 
El desplazamiento físico de caballero y escudero ha sido condición de base para el proyecto de movilidad. Sin el nomadismo los personajes habrían quedado arrinconados en los espacios urbanos, donde habría ocurrido su irremediable neutralización a manos de los AIEs, tal y como ocurre con sus émulos avellanedescos. La errancia que señalamos es una de las principales coincidencias que se dan entre don Quijote y un personaje muy posterior, Roque Guinart, quien lleva una vida que sorprende al caballero precisamente por sus constantes transferencias. La equidad entre dichos personajes se advierte, asimismo, en la base ideológica de sus respectivas convicciones sobre la vida. Guinart cree en una justicia basada en la desapropiación de los ricos para permitir el mejoramiento de los pobres. Esta creencia no pasa inadvertida para don Quijote, quien lo invita a integrarse a las filas de la caballería; ello a pesar de sus diferencias metodológicas, pues aun cuando el caballero reconoce el mérito ideológico de justicia que orienta a Guinart, no aprueba sus prácticas. Sobre esto, hay que recordar que para el hidalgo la caballería iguala todas las cosas y representa una sociedad que elimina la distancia entre criado y amo. La pobreza que quiere extirpar Guinart es material, pero también moral, pues aspira a traer dignidad a los desfavorecidos que han sido maltratados con políticas segregacionistas desde Carlos I, que ordenó la evacuación de las ciudades de los mendigos y reprimió el nomadismo, condición clave, como se ha señalado, para la búsqueda del ascenso social.

\section{La respuesta de Avellaneda}

En su prólogo, e inmediatamente después de evocar al Santo Oficio y su poder represor enmascarado en los supuestos de 'seguridad y limpieza', Avellaneda nos anuncia su intención de emprender una comedia en la que tengan centro las 'simplicidades' de Sancho. Estas dichas simplicidades superan en mucho lo que podríamos entender como actos ingenuos o descuidados, pues se concentran en un aspecto que, si bien Cervantes usó como recurso de entrada, luego le permitió alimentar la compleja naturaleza de la reversibilidad de su personaje. El segundo Sancho no va nunca allende las orillas de su coto mental. No obstante, su dibujo como ser limitado es del todo coherente con el desenlace de la obra: Sancho -junto a su esposa, que también acabará bufonizada- se queda a servir en el 
ambiente cortesano, completamente ajeno al destino que ha tenido don Quijote, de quien no vuelve a ser escudero y al que incluso ayuda con algún dinero para regresar a casa.

El supuesto de reorientación ideológica planificado por Avellaneda explicaría, asimismo, el predominio de aristócratas que comparecen en parte importante del argumento ideando y gastando bromas a la pareja central. Esta prevalencia no parece gratuita, sino deliberada y concebida como respuesta a un sistema de representaciones sociales visiblemente contestatario al original cervantino, lo cual no autoriza a afirmar que Avellaneda haya pertenecido al grupo selecto de los llamados 'caballeros de buen gusto', pero sí que fue afín a sus intereses. Los nobles retratados forman una comunidad ociosa y desprovista de conciencia social integradora. Se trata de un estamento que no desea perder prebendas y que ve con recelo las aspiraciones arribistas de la población empobrecida. A esta comunidad que alega la preservación de las jerarquías se añade el influjo de una iglesia obsesionada en mantener a los fieles sensibilizados con el más allá. Ambas posiciones difieren de Cervantes, quien, aun cuando es capaz de reconocer el poder de los privilegiados, no se abstiene de dirigirles sutiles críticas como las que apunta a los duques y al conde de Salazar, a quien ve como epítome de la intolerancia institucionalizada, según lo enseñan estas palabras de Ricote: "porque con el gran don Bernardino de Velasco, conde de Salazar, a quien dio su majestad cargo de nuestra expulsión, no valen ruegos, no promesas, no dádivas, no lástimas." (Cervantes II, 65, 849). En definitiva, un encumbrado que no distingue la misericordia de la justicia. En Avellaneda no existen censuras de este tipo. Sus potentados son siempre hegemónicos y factor decisivo de estabilidad social.

Además del predominio nobiliario, tampoco se inadvierte el protagonismo de Sancho por sobre don Quijote y el énfasis con que se expone su rusticidad elemental. El escudero es confinado al papel de mero bufón, destituido de la astucia ocasional y creciente que le imprimió Cervantes, cambios que con el avance de los acontecimientos le permitirán construir una simetría análoga a la reversibilidad de su amo. Como sintetiza Iffland:

Una obra centrada en el medio cortesano, con Sancho de protagonista bufonesco, sería una proyección completamente natural de todo lo que va sucediendo dentro de los parámetros ideológicos y artísticos de la obra. La vaguedad sobre una próxima tanda de aventuras protagonizadas por don Quijote se explica si tomamos en cuenta que ya se ha agotado su utilidad para impartir lecciones. Sancho, en cambio, tiene futuro en su papel de bufón rústico cuyas payasadas ayudan a confirmar la 
superioridad aristocrática y urbana sobre las masas campesinas (Iffland 375).

La reorientación de Avellaneda parece buscar, pues, la fijación de las jerarquías sociales, la inamovilidad del campesino y la afirmación de la heredad como mérito superior a las obras. Con estos principios pretende relativizar las virtudes defendidas por Cervantes y descalificar cualquier proceso de desestabilización social o de debilitamiento de los AIEs. La motivación didáctica ${ }^{6}$ del epígono, descendiente de las premisas neoaristotélicas de su tiempo, lo llevan a eliminar las pulsiones individualistas del primer Quijote y a reemplazarlo por el determinismo social y el castigo divino que resulta de las infracciones. Sus dos novelas intercaladas (El rico desesperado y Los Felices amantes) tratan, por ejemplo, del castigo y la recompensa que advienen de un mismo tema: la transgresión al voto religioso. En ambas narraciones comparecen dos cuestiones que ocuparon sensiblemente a la teología de la época: el libre albedrío y la intervención divina. Con los desenlaces diagonales de sus historias incrustadas, Avellaneda expuso y comparó las dos consecuencias que la renuncia voluntaria al voto puede aparejar. Siguiendo a Trento (canon $\mathrm{X})$, defiende que la justificación es inaccesible sin el concurso de la justicia de Cristo.

De esta manera, con un alienado recluido $^{7}$, reincidente y sin sabiduría y un campesino bufonizado, Avellaneda proyecta un final que claramente anula (o busca anular) las potencialidades transgresora y subversivas que debió percibir en su antecesor, reduciendo a meras impropiedades sus implicaciones ideológicas. Entre otras evidencias, este tipo de disensión quedó expresada en el prólogo imitativo con la identificación semántica entre los 'hierros' de la cárcel, donde Cervantes declara haber concebido su obra, y los 'yerros' o errores atribuidos a su ejecución e ideología.

\subsection{El énfasis en los aparatos represivos de poder}

La maquinaria burlesca ideada por Avellaneda está articulada por un sistema de validación y defensa de los AREs. Al igual que los AIEs, estos aparatos presentan modos

\footnotetext{
${ }^{6}$ William Hinrichs ha reflexionado sobre la motivación primordial de Avellaneda en estos términos: "Pocos entendemos que no la escribe para insultar, sino para incitar a don Miguel de Cervantes. Su respuesta de quinientas páginas no es, por lo tanto, una afrenta, sino un elogio." (Hinrichs 113)

${ }^{7}$ Según Avellaneda, recordemos, la novela pretende enseñar a no ser loco.
} 
organizados e institucionalizados, pero podrían ser también espontáneos e improvisados, como el grupo de muchachos que rodean y castigan al caballero en su paso por los centros urbanos. Los chicos, en apariencia inocuos y traviesos, representan a la sociedad cuerda y sirven de preámbulo censor para las actividades directamente coercitivas que emprenderán verdugos, alguaciles, ministros y escribanos.

En el episodio del azotado (cap. VIII), el primer ciudadano que enfrenta a don Quijote es el escribano. Cuando el caballero no permite que la comitiva represiva avance, el funcionario estatal le sale al paso y lo increpa de un modo tal que don Quijote devuelve la agresión con una embestida. Los alguaciles y ministros -formalizaciones del ARE judicialcreen que se trata de un pariente del condenado que intenta interferir en su suerte y claman con el grito de “¡Favor a la justicia! ¡Favor a la justicia!” (Fernández de Avellaneda, 2014:92). Lo relevante de esta intervención es que se hace equivaler la locura del caballero con una falta al orden público, un hecho que tendrá consecuencias definitivas en el tratamiento del personaje en el desenlace narrativo.

En definitiva, las burlas son una variación de las sanciones, que se concretizan en arrestos y reclusiones. La única crítica moral que Avellaneda dirige a los abusos nobiliarios es un tímido adjetivo (pesada) vocalizado por el narrador: “(...) llamó a los pajes, que estaban no poco desatinados de la pesada burla" (Fernández de Avellaneda, 2014:139). Sobre la naturaleza de estas actividades aristocráticas, Gómez Canseco recuerda que: "En Avellaneda, al modo común de la época, el concepto de 'buen gusto' estaba en relación con la eutrapelia y con la afición a las facecias y las burlas moderadas y cortesanas.” (Fernández de Avellaneda, 2005:14, 410).

La insistencia en las burlas sugiere que se trata de algo superior al mero esparcimiento de los privilegiados. La imagen simbólica más decisiva de los AREs y de la equidad entre locura y delito probablemente sea la cadena con que se ata al caballero en su forzado regreso a la aldea. Los encarcelamientos recorren la novela como consecuencia de lo que Avellaneda debió considerar como rasgos inalterables de las personalidades centrales, a las que describió con calificativos sin matices: “(...) porque estaba rematadamente loco, y Sancho ayudaba más a todo con sus simplicidades y boberías". (Fernández de Avellaneda, 2014:109). Las 'boberías' parecen compatibles con la crítica que hace el escudero al ARE judicial, según se advierte en el cansancio que este siente ante 
la omnipresencia represiva: “¿Sabe con quién querría yo que don Quijote, mi señor, hiciese pelea? Con estos demonios de alguaciles y porteros que nos hacen a cada paso terribles desaguisados" (Fernández de Avellaneda, 2014:334). Sin embargo, estas reacciones subversivas son efímeras y estériles y no pueden prosperar en este ámbito, pues está previsto que un alienado mental y un bobo ignorante deben supeditarse a los AIEs. Avellaneda defiende la necesidad de esta subordinación como virtud para la edificación de España: “(...) siendo obedientes los inferiores a los superiores, con buen orden y concierto, se hacen firmes y estables y dificultosamente son rompidos y desbaratados" (Fernández de Avellaneda, 2014:51). De esta forma, los marginados de la sociedad (mendigos, prostitutas, criminales, vagos y locos) deben ser silenciados para que el poder opere sin obstáculos y así acabar con la inconveniente impresión de desorden que estas masas suministran a los sectores más favorecidos.

\subsection{La reversibilidad negada}

La creciente reversibilidad de conducta y percepción del mundo del don Quijote original debió constituir un entrevero para las representaciones sociales y artísticas postuladas por Avellaneda. Parece claro que para responder a Cervantes se valió de una articulación entre una línea ideológica contestataria y un concepto de literatura fiel al modelo horaciano. Este último se manifiesta en la estrategia de restringir a los personajes a los estrictos parámetros del decoro conforme los cánones prescriptivos. El aspecto ideológico, por su parte, implicó la supresión de las dualidades ambivalentes (tonto-listo, loco-sabio) para eliminar las potencialidades cuestionadoras o desestabilizadoras del orden sociopolítico que Avellaneda busca preservar. Resultado directo de estas representaciones es la unicidad en la configuración comportamental y discursiva tanto de personajes centrales como secundarios, negándoseles así todo tipo de desarrollo, matices o ambigüedades $^{8}$. En palabras de Gómez Canseco "Nunca [la trama] da lugar a la reflexión

\footnotetext{
${ }^{8}$ Martín Morán ha demostrado cómo está rigidez se vierte a los diálogos avellanedescos: “El diálogo es el corazón pulsante del Quijote de Cervantes. La crítica, por lo general, se muestra conforme con el aserto anterior. La mayor parte de ella acepta también que la capacidad de los personajes cervantinos de comunicar sus vivencias con el otro, y de irse haciendo recíprocamente y en relación con el mundo traza una nueva perspectiva para el género narrativo. A esta dimensión compartida de las experiencias no llegan, desde luego, los personajes de Avellaneda, encerrados como están en los límites de su máscara caracterial." (Martín Morán 75).
} 
de los personajes o a su evolución: sus héroes son siempre idénticos a sí mismos y actúan como autómatas" (Fernández de Avellaneda, 2005:116). Para Iffland (1999), esto que podría parecernos una limitación de talento narrativo debe ser entendido como la tentativa de refutar radicalmente las eventuales posibilidades de ascenso social que sugiere el texto cervantino.

Cabe complementar que para los AIEs (recordando que estos se presentan bajo la forma de instituciones distintas y especializadas), el nomadismo tenía dos significados muy concretos: uno inmediato, el abandono de las tareas de producción, y otro proyectivo, la movilidad social. El loco, despojado de sus luces y de su capacidad de emprendimiento, es un ser sin posibilidades de participación en la sociedad y sólo le cabe el destino de la reclusión, la cual no tiene como único objetivo la sanación, sino también la punición judicial, pues el extravío es entendido como una afrenta al aparato jurídico moral. Para demostrar que una institución de salud mental podía operar como ARE judicial, González Duro (Iffland, 1999) ejemplifica el caso del Hospital de Inocentes de Sevilla durante el siglo XVII. En esta entidad era el administrador y no el médico quien daba el alta, la que, por su parte, era supervisada por dos representantes del poder judicial: un oidor de la Audiencia y un juez. Esta posición ideológica de Avellaneda será contrarrefutada por Cervantes a través de sus continuos énfasis en la compleja dualidad interna de sus personalidades medulares.

\subsection{La refutación de las aspiraciones de movilidad social}

Al comparar los objetivos que los autores prologan en sus respectivos Quijotes advertimos que, al menos inicialmente, repiten la vindicación de la justicia social tomando como modelo inspirador la estatura mítica del héroe caballeresco. No obstante, esta convergencia se anula en sus propias proyecciones. Si, por ejemplo, para el caballero cervantino la remuneración será la fama, el prestigio y el amor elevado, para su epígono será el peculio, según lo confirma esta arenga dirigida a Sancho:

(...) y juntamente ganaremos honra y fama para nosotros y nuestros sucesores, conservando y aumentando la de nuestros antepasados; tras que adquiriremos mil reinos y provincias en un quita allá esas pajas, con que seremos ricos y 
enriqueceremos nuestra patria. (Fernández de Avellaneda, 2014:35)

Dicha aspiración condice con la escena en que don Quijote extrae de un baúl las ricas prendas de don Álvaro y las viste imitando los modos aristocráticos que desea emular como parte de sus aspiraciones cortesanas. Nada más distante del don Quijote original, que busca precisamente lo contrario: alejarse de esta comunidad privilegiada por considerarla resumen de la inacción y la fruslería.

En otro orden, mientras el héroe imitativo es arribista y castigado por ello, la segunda Aldonza rechaza radicalmente la promoción social que este le endilga pues tiene plena conciencia de su nombre y de la condición que le cabe:

Que por el siglo de mi madre, que si otra vez me escribe de emperatriz o de reina, poniéndome nombres burlescos, como es "A la infanta manchega Dulcinea del Toboso, y otros semejantes que me suele escribir, que tengo de hacer que se le acuerde. Mi nombre es Aldonza Lorenzo o Nogales, por mar y por tierra." (Fernández de Avellaneda, 2014:31).

Esta Dulcinea aparece para castigar lo que entiende como burla, afirma su posición en la jerarquía social y desaparece para siempre. Su brevísima figuración nos adelanta que las aspiraciones sociales que surgirán en el relato no serán más que proyectos febles y expuestos a la condena ajena.

\section{4.- Cervantes se distancia de Avellaneda}

El título de este apartado se infiere del giro narrativo que Cervantes imprimió a la segunda parte de su novela. Para un número importante de especialistas Cervantes estaba redactando el capítulo 59-II cuando se enteró de la existencia del otro Quijote y se apresuró a elaborar su contestación. La suposición contraria, la de que Cervantes refaccionó partes anteriores al capítulo mencionado, cobra probabilidad si atendemos a, por ejemplo, el inicio de la segunda parte. En el primer capítulo de 1615 encontramos un loco recluido, simétrico al enajenado erudito de 1614 y al propio don Quijote original ${ }^{9}$. Por probable influjo

\footnotetext{
${ }^{9}$ Este contacto argumental ha despertado la siguiente inquisición de Álvarez Roblin: "Si realmente se trata de una imitación [por Cervantes], ¿por qué las coincidencias literales son casi inexistentes? Y, sobre todo, ¿qué sentido tiene aquí la reescritura? ¿Es acaso esta historia, rechazada por don Quijote, una versión en miniatura — de signo inversivo- del desenlace de Avellaneda?" (Álvarez Roblin 93).
} 
erasmista, Cervantes debió desaprobar la insistencia avellanedesca de presentarnos la locura como un delito. Con esta estrategia, profundamente afincada en una ideología represiva, el epígono había eliminado de manera drástica la reversibilidad del personaje principal y con ella toda la elocuencia de su proyecto de encumbramiento social y de libertad.

Las respuestas cervantinas contra este orden de cosas son tanto explícitas como implícitas. Las primeras son visibles en el segundo prólogo y en las condenas que hace del libro contendor en los capítulos II, LXII, LXX, LXXI, LXII. Las implícitas constan en II, LIX y en el decurso de toda la obra mediante estrategias como el énfasis en la reversibilidad, el desvío de don Quijote hacia Barcelona y muy probablemente el desenlace y muerte del propio protagonista.

Para reforzar la descalificación del epígono, Cervantes introdujo en su propia narrativa a uno de los principales perpetradores de las burlas al segundo don Quijote, responsable en gran medida de la consignación ideológica de la superioridad social de la nobleza: don Álvaro Tarfe. El personaje de la continuación entra a la escena cervantina en 72-II y desde un comienzo es interrogado por don Quijote para que corrobore la falsedad de sus imitadores. Mientras el Álvaro Tarfe ${ }^{10}$ original es un encumbrado que se justifica en la narrativa como burlador y promotor del encierro del caballero, el noble cervantino se muestra visiblemente discreto y respetuoso de los personajes de 1615. Cervantes lo aprovecha para que sea un personaje de su propio rival el que demarque la distancia ideológica entre ambos. Y logra el acometido no solo mediante el artificio de hacerlo comparecer ante notario para que confirme la veracidad de su personaje, sino en la descripción reveladora que ofrece del segundo Sancho: "Más tenía de comilón que de bien hablado, y más de tonto que de gracioso" (Cervantes 880). Esta semblanza refuta no solo la reversibilidad del personaje sino cualquier defensa simbólica de afanes arribistas. La

${ }^{10}$ Juan Gabriel Vásquez (2009) señala que la irrupción de Tarfe es una de las innovaciones que tornan al Quijote en el libro creador de la novela moderna. Sobre el personaje dirá: "Pues todos los procedimientos técnicos del Quijote - el manuscrito de Cide Hamete, la traducción de ese manuscrito, la mención de 'un tal Cervantes' en el libro, la inclusión de la Primera parte y de la falsa Segunda en la Segunda verdadera- son un renovado esfuerzo dirigido a que el lector no pierda de vista esta verdad: que ningún relato es totalmente verdadero, ni ninguno totalmente falso. Con este relativismo - vale decir: con esta ironía- Cervantes funda la novela como la conocemos hoy. Y don Álvaro Tarfe, la criatura del enemigo, viene a convertirse entonces en portador de buenas noticias." (Vásquez 132) 
respuesta del Sancho original aparece adelantada en 62- II, vale decir, pocos capítulos después de que se haya hecho pública la noticia de la imitación. Al responder a una oferta de albondiguillas ofrecidas por don Antonio Moreno el escudero contesta: “(...) y quienquiera que hubiere dicho que yo soy comedor aventajado y no limpio, téngase por dicho que no acierta." (Cervantes 824). Esta aserción es corroborada inmediatamente por don Quijote: “(...) la parsimonia y limpieza con que Sancho come se puede escribir y grabar en láminas de bronce, para que quede en memoria de los siglos venideros" (Cervantes 824).

Avellaneda no nos proporciona ejemplos similares de empatía. Nos entrega, en cambio, un final que Cervantes debió sentir como un rebajamiento inadmisible para su héroe. De ahí que no sea en absoluto incierto que Avellaneda haya sido la causa indirecta de la muerte del caballero.

\section{Palabras finales}

Las directrices ideológicas de las obras examinadas suelen manifestarse de maneras tan imbricadas en el tejido de las aventuras que nos han motivado al análisis de algunas de las posibles motivaciones que pudieron tener Cervantes y Avellaneda al momento de elaborarlas. La importancia de tratar estas motivaciones nació de dos formulaciones: la primera procede de James Iffland (1999), quien se pregunta qué aspectos concretos del

Quijote cervantino incomodaron tanto a Avellaneda al punto de emprender su refutación ideológica. La segunda es de Gómez Canseco de quien reproducimos literalmente su posición:

No creo que Avellaneda reflexionara sobre sus objetivos literarios antes de ponerse a escribir la obra. Los errores en la composición y los descuidos en la trama corroboran la idea de un hombre lanzado a la escritura más como consecuencia de un golpe de bilis que de un ejercicio de especulación literaria”. (Fernández de Avellaneda, 2005:110)

Creemos que ambas visiones no son incompatibles. El golpe de bilis a que alude Canseco comporta también una motivación. Ello refuerza la idea de que el Quijote de 1614 
fue concebido y luego ejecutado como una contestación y que en este tránsito hubo implicaciones ideológicas que dieron contenido y coherencia a la novela.

Si bien toda obra pertenece a su tiempo, no toda creación debe de fundamentarse en un proyecto premeditadamente ideológico, sea este explícito o implícito. De ahí la necesidad de diferenciar entre motivaciones manifiestas y motivaciones inferidas. La manera como Avellaneda leyó el texto cervantino lo indujo a responder estética e ideológicamente a su modelo. Así, la incomodidad que le despertó la obra lo llevó a reorientar el Quijote original y a dirigirlo hacia un ámbito de creencias que él consideraba seguro y libre de amenazas.

La obra de Avellaneda revela a un autor que debió tener una amplia conciencia de la crisis socio-económica que afectaba a España y de las tensiones sociales que esta aparejaba. Las aspiraciones de un grupo social necesitado y postergado colidió, como se sabe, con la rígida jerarquía social heredada de la Edad Media. Avellaneda respondió a estas turbulencias con la simétrica rigidez de sus personajes. No por otra razón Gómez Canseco ha señalado que Avellaneda "se muestra como defensor de un orden establecido, como la encarnación de la España oficial” (Fernández de Avellaneda, 2005:89). Un orden establecido, claro está, por los Aparatos Ideológicos y Represivos del Estado. El don Quijote imitativo, tan alienado que ni siquiera puede amistar con su escudero, es trasunto de este orbe mundano y divino que niega los entresijos sociales que puedan amenazar su descomposición.

\section{Bibliografías}

Althusser, Loius. "Ideologia e Aparelhos Ideológicos do Estado (Notas para uma Investigação)". Um mapa da ideologia. 5ª reimpresión. Org. Slavoj Žižek. Rio de Janeiro: Contraponto, 2013.

Álvarez Roblin, David. "Propuestas para un nuevo enfoque de la relación CervantesAvellaneda". El otro Don Quijote. La continuación de Fernández de Avellaneda y sus efectos. Ed. Hanno Ehrlicher. Mesa redonda, Nueva Serie 33. Augsburgo: Universität Augsburg Institut für Spanien, Portugal- und Lateinamerikastudien (ISLA) Instituto de Investigaciones sobre España, Portugal y América Latina, 2016octubre de 2018.75-92.

https://opus.bibliothek.uniaugsburg.de/opus4/frontdoor/index/index/docId/3704

Blasco, Javier. "Avellaneda, secular enigma cervantino" Insula, abril 2005, Octubre 2018. 700-701. http://uvadoc.uva.es/handle/10324/2432 (25/06/2018). 
Cervantes, Miguel de. El ingenioso Hidalgo don Quijote de La Mancha. Ciudad de México: Tomo, 2005.

Close, Anthony. La concepción romántica del Quijote. Barcelona: Crítica, 2005.

Ehrlicher, Hanno. "La artificiosidad aumentada. Avellaneda como catalizador de la narrativa del Quijote". El otro Don Quijote. La continuación de Fernández de Avellaneda y sus efectos. Mesa redonda, Nueva Serie 33. Ed. Hanno Ehrlicher Augsburgo: Universität Augsburg Institut für Spanien, Portugal- und Lateinamerikastudien (ISLA) Instituto de Investigaciones sobre España, Portugal y América Latina, 2016. Septiembre de 2018. 55-74.

https://opus.bibliothek.uni-augsburg.de/opus4/frontdoor/index/index/docId/3704

Fernández de Avellaneda, Alonso. El ingenioso Hidalgo don Quijote de La Mancha.

Ed. Luis Gómez Canseco. Barcelona: Juventud, 2005.

Fernández de Avellaneda, Alonso, El ingenioso Hidalgo don Quijote de La Mancha. Ed.

Luis Gómez Canseco. Madrid: Real Academia Española, 2014.

Feros, Antonio. "Por Dios, por la Patria y el Rey": El mundo político en tiempos de Cervantes. España en tiempos del Quijote. Dirs. Antonio Feros y Juan Gelabert. Madrid: Taurus, 2005.

Hinrichs. William. "Los felices continuadores de Avellaneda: expansión del mundo Quijotesco después de 1614." El otro Don Quijote. La continuación de Fernández. de Avellaneda y sus efectos. Ed. Hanno Ehrlicher. Mesa redonda, Nueva Serie 33, Augsburgo: Universität Augsburg Institut für Spanien, Portugal- und Lateinamerikastudien (ISLA) Instituto de Investigaciones sobre España, Portugal y América Latina, 2016. Octubre de 2018. 93-109, https://opus.bibliothek.uni-augsburg.de/opus4/frontdoor/index/index/docId/3704

Iffland, James. De fiestas y aguafiestas: risa, locura e ideología en Cervantes y Avellaneda. Madrid: Iberoamericana, 1999.

Martín Morán, José Manuel. "El diálogo en las dos segundas partes del Quijote." El otro Don Quijote. La continuación de Fernández de Avellaneda y sus efectos. Ed. Hanno Ehrlicher. Mesa redonda, Nueva Serie 33. Augsburgo: Universität Augsburg Institut für Spanien, Portugal- und Lateinamerikastudien (ISLA) Instituto de Investigaciones sobre España, Portugal y América Latina, 2016. Septiembre de 2018. 75-92. https://opus.bibliothek.uniaugsburg.de/opus4/ frontdoor/index/index/ docId/3704 Padilla, Ignacio. El diablo y Cervantes. México: F.C.E., 2005.

Rodríguez López-Vázquez, Alfredo. "Introducción". Alonso Fernández de Avellaneda, El Quijote apócrifo. Ed. Alfredo Rodríguez López Vázquez. Madrid: Cátedra, 2011

Van Dijk, Teun. Ideología. Un enfoque multidisciplinario. Barcelona: Gedisa, 1999.

Vásquez, Juan Gabriel. El arte de la distorsión. Bogotá: Alfaguara, 2009.

Villalobos Lara, Raquel Elizabeth. El Quijote en Chile. Primera edición y estudios bibliográficos desde 1863 a 1947. Santiago, Chile: RIL, 2017.

Vincent, Bernard. "La sociedad española en la época del Quijote". España en tiempos del Quijote. Dirs. Antonio Feros, y Juan Gelabert. Madrid: Taurus, 2005. 